\title{
Portfolio optimisation for hydropower producers that balances riverine ecosystem protection and producer needs
}

\author{
X. A. Yin, Z. F. Yang, and C. L. Liu \\ Correspondence to: Z. F. Yang (zfyang@bnu.edu.cn) \\ Received: 28 November 2013 - Published in Hydrol. Earth Syst. Sci. Discuss.: 23 December 2013 \\ Revised: - - Accepted: 28 February 2014 - Published: 8 April 2014
}

State Key Laboratory of Water Environmental Simulation, School of Environment, Beijing Normal University, Beijing, China

\begin{abstract}
In deregulated electricity markets, hydropower portfolio design has become an essential task for producers. The previous research on hydropower portfolio optimisation focused mainly on the maximisation of profits but did not take into account riverine ecosystem protection. Although profit maximisation is the major objective for producers in deregulated markets, protection of riverine ecosystems must be incorporated into the process of hydropower portfolio optimisation, especially against a background of increasing attention to environmental protection and stronger opposition to hydropower generation. This research seeks mainly to remind hydropower producers of the requirement of river protection when they design portfolios and help shift portfolio optimisation from economically oriented to ecologically friendly. We establish a framework to determine the optimal portfolio for a hydropower reservoir, accounting for both economic benefits and ecological needs. In this framework, the degree of natural flow regime alteration is adopted as a constraint on hydropower generation to protect riverine ecosystems, and the maximisation of mean annual revenue is set as the optimisation objective. The electricity volumes assigned in different electricity submarkets are optimised by the noisy genetic algorithm. The proposed framework is applied to China's Wangkuai Reservoir to test its effectiveness. The results show that the new framework could help to design eco-friendly portfolios that can ensure a planned profit and reduce alteration of the natural flow regime.
\end{abstract}

\section{Introduction}

Since the global electricity reform process began in the 1980s (Zelner et al., 2009; Wang and Chen, 2012), and especially after the 1990s, market-oriented reforms in the electric power industry were implemented in many countries to allocate electricity more efficiently through market mechanisms (Cai et al., 2009, 2011; Williams and Dubash, 2004; Tsai, 2011; Wu, 2012). In the process of reform, vertically integrated electricity utilities were restructured and unbundled, and competition has been introduced into generation as well as the wholesale and retail segments of the industry (Pollitt, 2009; Holmberg, 2011; Mulder, 2011). In deregulated markets, hydropower producers usually own generation resources and are allowed to participate in any submarkets such as bilateral contract and spot markets (Karandikar et al., 2010; Ramos et al., 2010). Maximising profits is usually their sole objective for participating in the market (Liu et al., 2009). To maximise profits, hydropower producers need to devise their own strategies for portfolio design (Shen and Yang, 2012).

Extensive research has been performed to optimise hydropower portfolios. Bjørgan et al. (1999) integrated the optimisation of future contract and power scheduling based on risk management in a static mean-variance framework, and the efficient frontier was used as a tool to identify a preferred contract portfolio. Using a continuous-time framework, Keppo (2002) proposed a model for optimal longterm electricity trading strategies and the associated production process by maximising production and terminal water reservoir level in the case of multi-reservoir hydropower systems. Fleten et al. (2002) used a four-stage stochastic programming model with 256 scenarios for simultaneous risk 
management via contracts and hydropower generation planning on a 1.5-year horizon. Shrestha et al. (2005) presented a portfolio management technique to optimise expected revenue for a hydropower producer, a scenario that utilises tree analysis with corrective recourse actions for probable scenarios. The effect of contract position adjustment is also analysed to minimise revenue variation from the expected values for risk-averse producers. Liu et al. (2009) present a stochastic linear programming framework for hydropower portfolio management with uncertainty in market prices and inflows on medium term, in which the uncertainty was modelled as a scenario tree using the Monte Carlo simulation method, to maximise the expected revenue over the entire scenario tree. These approaches could effectively optimise hydropower portfolios and maximise the total profit of hydropower producers. However, none of the previous research on hydropower portfolio optimisation considered the need to protect riverine ecosystems.

The determined portfolios could give two important results: (1) the optimal electricity volume that should be generated for each period (day, week, month, etc.); (2) the optimal allocation of the generated hydropower among different electricity submarkets. The electricity volume determines the water volume that should be released to the downstream rivers, and in turn determines the degree of flow regime alteration. Flow regime alteration is the major cause of riverine ecosystem degradation (Bunn and Arthington, 2002; Babel et al., 2011; Kern et al., 2012; Bhatt and Khanal, 2012). Due to the difference of electricity price among different submarkets, the electricity allocation among different submarkets as well as the total generated electricity volume determines the revenue of hydropower producers. Thus, the determination of hydropower portfolio before hydropower generation is essential for both riverine ecosystem protection and producer needs. Although profit maximisation is the major objective for producers in deregulated markets, the need to reduce flow regime alteration must be incorporated into the process of hydropower portfolio optimisation for riverine ecosystem protection, especially with the background of increasing attention to environmental protection and stronger opposition to hydropower generation (Jager and Smith, 2008; Chen et al., 2012).

Many new reservoir operating methods have been proposed to better sustain environmental flows (e-flows, the volume of water that should remain in a river and the variation of this provision over time to maintain specific indicators of ecosystem health) in rivers (Richter, 2010; Shiau and $\mathrm{Wu}$, 2010; Brown and King, 2012). These methods are river protection approaches at the hydropower generation stage. Portfolio determination is a task that occurs before hydropower generation. The designed hydropower portfolio can significantly influence reservoir operation through the influence of planned electricity volume and in turn the water volume released to the downstream rivers (Chen et al., 2012; Yin et al., 2011, 2012). Even if the reservoir operating rules are refined, their ecological protection effects may not be as effective as expected under the conditions of improperly designed portfolios. Meanwhile, the effects of portfolio optimisation on river protection need to be displayed by the influence on hydropower operation. Research on the optimal portfolios must be performed with the consideration of both economic benefits and ecological needs, which can provide the basis for developing eco-friendly reservoir operating rules.

This research seeks to remind hydropower producers of the requirement of river protection when they design the portfolios and to help the producers design eco-friendly portfolios. In this work, we extend previous research on hydropower portfolio optimisation and establish a framework to determine the optimal portfolio of a hydropower reservoir, accounting for both economic benefits and ecological needs. This framework may help mitigate the impact of hydropower generation on riverine ecosystems, especially for the situation where the tension between river protection and power generation is very severe.

\section{Methods}

\subsection{Framework for determining optimal hydropower portfolios for both riverine ecosystem and producer needs}

\subsubsection{Determining the submarkets for participation}

Submarkets available for hydropower are not the same for each country in the world. Three common markets are bilateral contract (future), day-ahead, and real-time balancing (Alaywan and Wu, 2002; Kranz et al., 2002). Day-ahead and real-time balancing markets are also called spot markets. Participants in the electricity market face the risks of unknown demand and price (Aggarwal et al., 2009; Eichhorn et al., 2009). To avoid revenue risks, hydropower producers and grid companies like to make long-term or mid-term electricity supply contracts, forming the bilateral contract market (Lin and Wu, 2008). In a bilateral contract, the trading power volume and power price are designed by the power producers and grid companies, and will not change during the contract period. In the day-ahead market, participants submit sell/bid offers for electricity for the following day. These offers consist of a quantity of energy to be sold or purchased and a desired price, where sell offers correspond roughly to each producer's marginal cost of energy production. The system operators then rank sell offers from least to most expensive; the last sell offer required to satisfy day-ahead forecast demand clears the market, and the marginal cost of increasing power supply by one additional megawatt determines the marketclearing energy price. Sellers with offers equal to or below this price then generate revenue equal to their respective bid quantities multiplied by the market-clearing price (Rothwell and Gomez, 2003). In the real-time balancing market, 
system managers coordinate an hourly real-time energy market, which is used to meet real-time electricity demand when it varies relative to day-ahead forecasts. An hourly real-time market clearing price is determined in a manner similar to that of the day-ahead market (i.e. via the ranking of bid/sell offers), and transactions are consummated as necessary to meet real-time demand (Lambert, 2001). The price in the spot market is uncertain, and it could be higher than, lower than or equal to the price in the contract market.

The hydropower producers choose the submarkets in which they want to participate. The selection depends to some extent on the risk preferences of the producers (Shrestha et al., 2005; Botterud et al., 2010). Risk-taking producers tend to participate in the spot market for possibly higher profit despite higher risk. Risk-averse producers participate in the bilateral contract market that is more reliable, although extensive research supports short-term bidding for potentially higher revenue. Risk-neutral producers tend to participate in both the bilateral contract and spot markets.

\subsubsection{Determining the rules for reducing flow regime alteration}

Although sustaining the natural flow regime is a basic principle for river protection and e-flow management (Poff et al., 1997, 2010), hydropower generation will inevitably lead to changes. A possible method to reduce flow regime alteration would be to apply a type of e-flow provision strategy (such as sustaining the minimum e-flows and ensuring several high flow pulses, etc.) and optimise the parameters related to the hydropower portfolio to minimise alteration of the natural flow regime or restrict the degree of alteration to a specified threshold. This method has been applied extensively in research (Black et al., 2005; Richter and Thomas, 2007; Jager and Smith, 2008; Yin et al., 2011, 2012).

Reservoir operators can use different e-flow provision strategies depending on their attitude toward riverine ecosystems. Sustaining the minimum e-flow is a commonly used strategy for real-world e-flow provisions. This strategy can provide basic protection of the riverine ecosystem, avoiding severe degradation. To sustain ecological functions related to high flows, some research proposes occasional high-flow releases for habitat improvement (Ligon et al., 1995; Gore et al., 2001; Renofalt et al., 2009). To better protect riverine ecosystems, hydropower operators can develop and apply more sophisticated e-flow strategies.

\subsubsection{Setting the portfolio optimisation objectives and constraints}

Maximising the total profit for a given planning period and reducing the degree of flow regime alteration are two objectives for hydropower portfolio design. However, the two objectives are in conflict and cannot be achieved simultaneously, which is a typical multi-objective problem.
To address this problem, the optimisation objectives need to be set first. An optimisation objective can be set as one of two conflicting objectives, i.e. maximising the overall profit for a given planning period or reducing the degree of alteration of the flow regime. The other objective can be set as one constraint by assigning a threshold accepted by the hydropower producers or river protectors. Alternatively, the two objectives could be integrated into one by some mathematical method such as compromise programming or weighted average.

Constraints for portfolio optimisation include maximum power generation capacity, water release capacity, reservoir maximum storage capacity, etc. If either of the two objectives is chosen as a single optimisation objective, the constraints also need to include the threshold for the other objective, i.e. the minimum acceptable overall profit or the maximum acceptable degree of flow regime alteration. The water mass balance also needs to be considered (Liu et al., 2009).

\subsubsection{Choosing the solution method under uncertainty}

In a deregulated market, portfolio optimisation is faced with the uncertainty of reservoir inflows and spot electricity prices (Fleten et al., 2002). A series of methods has been developed to obtain optimal solutions under uncertainty, such as stochastic dynamic programming, stochastic dual dynamic programming, stochastic programming combined with scenario trees, and noisy genetic algorithms (Chang et al., 2005; Chen, 2003; Chen et al., 2007). The optimisation method needs to address these uncertainties.

\subsection{Methods used in the case study}

\subsubsection{Range of variability approach}

The range of variability approach (RVA) (Richter et al., 1996, 1997, 1998) has been widely used for assessing flow regime alteration and directing hydraulic facility operations (Galat and Lipkin, 2000; Shiau and Wu, 2004, 2006, 2007; Zhang et al., 2009). According to the RVA, a range of variation for each hydrological indicator was derived from the natural hydrological time series and was set as the flow management target. A range defined by the 75 th and 25 th percentile flows has been recommended as the management target (Richter et al., 1998). The degree of alteration, $D_{m}$, was used to measure the deviation of the impacted flow regime from the natural one for the $m$ th hydrologic indicator, which was defined by

$D_{m}=\left|\frac{N_{\mathrm{o}, m}-N_{\mathrm{e}, m}}{N_{\mathrm{e}, m}}\right| \times 100 \%$,

where $N_{\mathrm{o}, m}$ was the observed number of post-impact years in which the value of the $m$ th hydrologic indicator fell within its RVA target range, and $N_{\mathrm{e}, m}$ was the expected number of post-impact years in which the indicator value fell within the RVA target range. The average degree of alteration of 
these hydrologic indicators was applied to quantify the river's overall impact, which can be expressed as follows:

$$
D=\frac{1}{G} \sum_{m=1}^{G} D_{m}
$$

where $D$ was the overall degree of flow regime alteration, and $G$ was the number of hydrological indicators ( $G$ is equal to 32 in this research). The degree of flow regime alteration can be categorised further into three levels: low alterations (values of $D$ between 0 and 0.33 ), moderate alterations (values of $D$ between 0.33 and 0.67 ), and high alterations (values of $D$ between 0.67 and 1.0) (Richter et al., 1998).

\subsubsection{Tennant method}

To illustrate the applicability of the proposed approach, we use the Tennant method (Tennant, 1976), a simple and widely used method, to determine seasonal minimum e-flows. Tennant method was recommended for e-flow assessment in the "technical guidelines for environmental impact assessment for ecological water usage, low temperature water and fish habitat facilities in the hydraulics projects" by the State Environment Protection Administration of China (2006), and was applied by the Haihe Water Conservation Commission (2008) for the Hai River basin. Accordingly, the wet season e-flow was set at $30 \%$ of average daily flow (ADF), and the dry season e-flow was set at $10 \%$ ADF. More sophisticated methods could be used to replace the Tennant method if enough hydrological, biological, and geomorphological data are available.

\subsubsection{Optimisation objectives and constraints}

In the following case study, the hydropower producer participates in the contract and day-ahead markets according to the hydropower generation planning. The goal for hydropower portfolio optimisation is to maximise the mean annual revenue subject to specified e-flow management requirements. These requirements include the e-flow provision strategy and the specified threshold for the degree of flow regime alteration. The optimisation problem can be expressed by the following equation:

$L=\max \frac{1}{T} \sum_{j=1}^{T} \sum_{k=1}^{365}\left(\mathrm{PC}_{k j} \cdot \mathrm{CL}_{k j}+\mathrm{PD}_{k j} \cdot \mathrm{DL}_{k j}\right)$,

which is subject to

$R_{k j} \geq \mathrm{EF}_{k j}$

$D \leq D_{0}$,

where $L$ denotes the overall optimisation objective, and $\mathrm{PC}_{k j}$ is the designed hydropower price in the hydropower supply contract for day $k$ of year $j$ (constant within 1 month, $\mathrm{RMB} \mathrm{kwh}^{-1}$ ); $\mathrm{CL}_{k j}$ is the designed hydropower volume in the hydropower supply contract for day $k$ of year $j$ (constant within 1 month, $\mathrm{kwh}) ; \mathrm{PD}_{k j}$ is the hydropower price in the day-ahead market for day $k$ of year $j\left(\mathrm{RMB} \mathrm{kwh}^{-1}\right)$; $\mathrm{DL}_{k j}$ is the bidding volume for power in the day-ahead market for day $k$ of year $j(\mathrm{kwh}) ; R_{k j}$ is the actual reservoir water release for day $k$ of year $j ; \mathrm{EF}_{k j}$ is the minimum e-flow for day $k$ of year $j ; D$ is the degree of actual flow regime alteration under a certain portfolio; and $D_{0}$ is the specified threshold of degree of flow regime alteration.

In the contract market, the producer and electricity grid make an agreement on the contract load for each month and the associated power price. In the day-ahead market, the producers need to determine the bidding volume for power. In this case, we assume that the producers first use inflow and the water in the reservoir to produce electricity to satisfy the contract load, and the producer will buy electricity from the market to satisfy the contract load only when the available electricity is not sufficient. Because the electricity cannot be stored, the bought electricity is set equal to the difference between the contract volume and the available power volume. We use the following equations to determine the bidding volume of power in the day-ahead market:

$$
\begin{aligned}
\text { if } \mathrm{AE}_{k j}-\mathrm{CL}_{k j}>0, \mathrm{DL}_{k j}= & \min \left[k_{k j}\left(\mathrm{AE}_{k j}-\mathrm{CL}_{k j}\right)\right. \\
& \left.\mathrm{PD}_{k j}, \mathrm{ME}-\mathrm{CL}_{k j}\right] ; \\
\text { if } \mathrm{AE}_{k j}-\mathrm{CL}_{k j} \leq 0, \mathrm{DL}_{k j}= & \mathrm{AE}_{k j}-\mathrm{CL}_{k j},
\end{aligned}
$$

where $\mathrm{AE}_{k j}$ is the available electricity volume that the hydropower plant can generate with the water in the reservoir and inflow for day $k$ of year $j(\mathrm{kwh})$; ME is the maximum electricity production capacity for 1 day $(\mathrm{kwh})$; and $k_{k j}$ is the parameter for day $k$ of year $j\left(\mathrm{kwh} \mathrm{RMB}^{-1}\right)$.

In Eq. (6), $k_{k j}\left(\mathrm{AE}_{k j}-\mathrm{CL}_{k j}\right) \mathrm{PD}_{k j}$ means that the higher the available electricity volume, the higher the day-ahead power price, and the higher the bidding volume for power. There may be some alternative and more sophisticated equations to replace $k_{k j}\left(\mathrm{AE}_{k j}-\mathrm{CL}_{k j}\right) P_{k j}$. The equation forms may also influence the revenue of hydropower producers and the effects of riverine ecosystem protection. Further research would be valuable to analyse the influence of equation forms and the optimal forms. The parameters $k_{k j}$ and $\mathrm{CL}_{k j}$ are two variables that need to be optimised. We assume $k_{k j}$ and $\mathrm{CL}_{k j}$ do not change over the period of 1 month and are the same for each year. Thus, $k_{k j}$ and $\mathrm{CL}_{k j}$ both have 12 values.

The real electricity produced by a hydropower reservoir is related to many factors such as the turbine release water discharge for power generation, the water head, and the coefficient of hydropower station power generation. The equations for hydropower generation have been presented extensively in the literature (e.g. Cheng et al., 2008; Li et al., 2009; Liu et al., 2011), and thus are not listed in the present paper. 


\subsubsection{Noisy genetic algorithm}

In hydropower portfolio optimisation, the future inflow and spot price are uncertain. The noisy genetic algorithm (NGA) is an effective method to determine the optimal values of parameters under uncertainty (Miller and Goldberg, 1996). The NGA has been applied for stochastic reservoir operation (Yun et al., 2010), ground water remediation (Aly and Peralta, 1999) and groundwater sampling network design (Wu et al., 2005) under uncertainty. In this research, NGA is applied to optimise the hydropower portfolio under uncertainty of flows and spot price.

The term noise can be defined as any factor that hinders the accurate evaluation of the fitness of a given trial solution. In this study, noise refers to the stochastic nature of the inflows and the power price in the day-ahead market. Most components in the NGA are the same as in a simple genetic algorithm (GA). The main difference between the NGA and GA is in the fitness function. In the NGA, the fitness value cannot be evaluated accurately because of the variability of monthly inflows. To overcome this difficulty, the fitness value is substituted by the expected fitness value. The details of the NGA can be found in Miller and Goldberg (1996) and Yun et al. (2010).

\section{Study site}

The Wangkuai Reservoir is a key hydraulic facility in the Hai River basin of China. The present effective storage capacity of the Wangkuai Reservoir is $6.52 \times 10^{8} \mathrm{~m}^{3}$, and the dead storage capacity is $0.88 \times 10^{8} \mathrm{~m}^{3}$. The catchment area of the reservoir is $3770 \mathrm{~km}^{2}$. The installed hydropower generation capacity of the Wangkuai Reservoir is $21.5 \mathrm{MW}$. In this research, we focus on the hydropower generation function of the Wangkuai Reservoir. The inflow data from 1971 to 1993 and the physical characteristics are used to simulate hydropower generation and optimise the hydropower portfolio. The producer considered in this paper is a price taker. The hydropower price in the day-ahead market is shown in Table 1 (Liu et al., 2009; Liu, 2009). The bilateral contract price between the Wangkuai Reservoir and the grid company is $0.36 \mathrm{RMB} \mathrm{kwh}^{-1}$ (Hebei Province Municipal Price Bureau, 2009).

In this research, we consider two e-flow provision strategies. In the first e-flow strategy, only the minimum e-flows are sustained. This strategy is most commonly used in realworld e-flow provisions. In the second e-flow strategy, in addition to the minimum e-flows, occasional high-flow (flows falling above the 75th percentile of all flows) releases are required to sustain the ecological functions related to high flows. In this research, we also assume for demonstration that after three high-flow events have occurred in a season, no further high flows are released, following the research by Vogel et al. (2007).
Table 1. Details of price variations in the day-ahead market.

\begin{tabular}{lcccc}
\hline Month & $\begin{array}{c}\text { Mean } \\
\left(\mathrm{RMB} \mathrm{kwh}^{-1}\right)\end{array}$ & $\begin{array}{c}\text { Maximum } \\
\left(\mathrm{RMB} \mathrm{kwh}^{-1}\right)\end{array}$ & $\begin{array}{c}\text { Minimum } \\
\left(\mathrm{RMB} \mathrm{kwh}^{-1}\right)\end{array}$ & $\begin{array}{c}\text { Standard } \\
\text { deviation } \\
\left(\mathrm{RMB} \mathrm{kwh}^{-1}\right)\end{array}$ \\
\hline 1 & 0.29 & 0.45 & 0.20 & 0.03 \\
2 & 0.28 & 0.45 & 0.20 & 0.03 \\
3 & 0.27 & 0.45 & 0.20 & 0.03 \\
4 & 0.29 & 0.45 & 0.20 & 0.04 \\
5 & 0.33 & 0.45 & 0.20 & 0.03 \\
6 & 0.37 & 0.45 & 0.20 & 0.04 \\
7 & 0.43 & 0.45 & 0.20 & 0.02 \\
8 & 0.40 & 0.45 & 0.20 & 0.04 \\
9 & 0.41 & 0.45 & 0.20 & 0.03 \\
10 & 0.38 & 0.45 & 0.20 & 0.05 \\
11 & 0.36 & 0.45 & 0.20 & 0.05 \\
12 & 0.32 & 0.45 & 0.20 & 0.04 \\
\hline
\end{tabular}

\section{Results}

Matlab 6.5 was used to apply NGA to determine the optimal hydropower portfolio. The generation size and evolution times were set at 600 and 1000, respectively. According to the Tennant method (Tennant, 1976), for the dry season (November to April), the seasonal minimum e-flow (10\% average daily flow) was $1.8 \mathrm{~m}^{3} \mathrm{~s}^{-1}$; for the wet season (May to October), the seasonal minimum e-flow (30\% average daily flow) was $5.4 \mathrm{~m}^{3} \mathrm{~s}^{-1}$. The threshold for the degree of flow regime alteration is set at 0.67 , the upper value for moderate alteration of the flow regime (Richter et al., 1996, 1997, 1998).

The optimised parameters are listed in Tables 2 and 3. These tables show that, during 5 of the 6 months in the wet season, the contract load under the second e-flow provision strategy is higher than the contract load under the first strategy because, under the second e-flow strategy, the reservoir is required to maintain several high flow pulses. The releases of greater flows required by the second e-flow strategy make higher contract loads reasonable. In addition, most (9 of 12) of the values for parameter $k$ under the first e-flow strategy are higher than the values of parameter $k$ under the second e-flow strategy, indicating that more water will be released to produce hydropower for the day-ahead market under the first e-flow strategy than under the second strategy.

The optimised mean annual revenues are $8.72 \times 10^{6} \mathrm{RMB}$ and $7.55 \times 10^{6} \mathrm{RMB}$ under the two e-flow provision strategies. The mean annual revenue under the second strategy is lower than the mean annual revenue under the first strategy, possibly because the extra water releases to maintain the high flows under the second e-flow strategy increase the proportion of electricity assigned in the contract market, reducing the proportion of electricity assigned in the spot market, which sometimes has higher prices than the contract price. Thus, the extra requirement to sustain high flows for river ecosystem protection potentially reduces the profits from hydropower generation. 
Table 2. Optimised monthly volume of hydropower in the contract for the Wangkuai Reservoir $\left(\times 10^{5} \mathrm{kwh}\right)$.

\begin{tabular}{lcccccccccccc}
\hline & Jan & Feb & Mar & Apr & May & Jun & Jul & Aug & Sep & Oct & Nov & Dec \\
\hline E-flow strategy 1 & 8.86 & 7.27 & 10.35 & 10.18 & 14.18 & 14.91 & 16.39 & 18.65 & 18.21 & 17.85 & 7.50 & 7.78 \\
E-flow strategy 2 & 9.21 & 7.86 & 9.47 & 9.26 & 17.69 & 18.35 & 19.47 & 21.11 & 20.81 & 17.36 & 8.75 & 7.70 \\
\hline
\end{tabular}

Table 3. Optimised value of $k$ for each month for the Wangkuai Reservoir (kwh RMB $\left.{ }^{-1}\right)$.

\begin{tabular}{lcccccccccccc}
\hline & Jan & Feb & Mar & Apr & May & Jun & Jul & Aug & Sep & Oct & Nov & Dec \\
\hline E-flow strategy 1 & 1.13 & 0.86 & 0.78 & 0.72 & 0.81 & 0.92 & 1.03 & 1.35 & 1.48 & 0.78 & 1.31 & 0.98 \\
E-flow strategy 2 & 0.96 & 0.76 & 1.32 & 0.64 & 0.84 & 0.68 & 0.64 & 1.08 & 0.72 & 0.92 & 0.96 & 0.88 \\
\hline
\end{tabular}

\section{Discussion}

\subsection{The influence and significance of incorporating environmental policies in portfolio management}

In previous research on portfolio optimisation, no specific rules were used for e-flow provision. The e-flows are supplied only by the water released for hydropower generation. This strategy is called non-e-flow for short. In the following section, we explore the influence of incorporating environmental policies in portfolio management by comparing revenue and flow regime alteration under the three e-flow strategies (i.e. the non-e-flow strategy and the two strategies established in the study site section), possibly helping to test the significance of incorporating environmental policies in portfolio optimisation.

We first determine the maximum mean annual revenue (without the constraint of the threshold for flow regime alteration degree) and corresponding degree of flow regime alteration under the three e-flow strategies. Under the three strategies, the maximum revenue and the corresponding degree of alteration are $12.38 \times 10^{6} \mathrm{RMB}$ and 0.82 (non-eflow strategy), $10.27 \times 10^{6} \mathrm{RMB}$ and 0.75 (strategy 1 ), and $9.37 \times 10^{6} \mathrm{RMB}$ and 0.68 (strategy 2 ). In comparison with the maximum annual revenue under the e-flow strategies 1 and $2\left(10.27 \times 10^{6} \mathrm{RMB}\right.$ and $\left.9.37 \times 10^{6} \mathrm{RMB}\right)$, the non-eflow portfolio optimisation method achieves higher revenue. However, the degree of flow regime alteration corresponding to this high revenue is 0.82 , obviously greater than the degree of alteration under the first and second e-flow provision strategies ( 0.75 and 0.68 ). Thus, although the non-e-flow portfolio optimisation method could yield higher revenue, it would come at the cost of degradation of the river ecosystem. To avoid severe degradation of riverine ecosystems, incorporation of an e-flow provision strategy into the hydropower portfolio optimisation process is necessary, at least with regard to sustaining the minimum e-flows.

The minimum degrees of flow regime alteration are also determined under the three e-flow strategies. The lowest degrees of alteration under the non-e-flow and the first e-flow
Table 4. Minimum degree of flow regime alteration under different planned revenues and different e-flow provision strategies.

\begin{tabular}{lccc}
\hline Revenue & $\begin{array}{c}9.37 \times 10^{6} \\
\text { RMB }\end{array}$ & $\begin{array}{c}6.63 \times 10^{6} \\
\text { RMB }\end{array}$ & $\begin{array}{c}3.89 \times 10^{6} \\
\text { RMB }\end{array}$ \\
\hline Non-e-flow strategy & 0.78 & 0.69 & 0.36 \\
E-flow strategy 1 & 0.72 & 0.61 & 0.31 \\
E-flow strategy 2 & 0.68 & 0.57 & 0.28 \\
\hline
\end{tabular}

strategies are the same (0.31) because, under the non-e-flow strategy, the releases are also greater than the minimum eflows in each month to achieve the minimum degree of flow regime alteration, and the contract load and $k$ are the same under the two e-flow strategies. Thus, if reducing the degree of flow regime alteration is taken as the key objective, it is not necessary to incorporate the minimum e-flow requirement as a constraint. The degree of flow regime alteration $(0.21$, corresponding to the revenue of $3.59 \times 10^{6} \mathrm{RMB}$ ) under the second e-flow strategy is obviously lower than the degree of flow regime alteration under the other two strategies, demonstrating the significance of assigning some high flows in the e-flow provision rules.

We further determine the minimum degree of flow regime alteration corresponding to the mean annual revenues of $9.37 \times 10^{6} \mathrm{RMB}$ (the maximum mean annual revenue that all the three strategies can achieve), $3.89 \times 10^{6} \mathrm{RMB}$ (the minimum mean annual revenue that all three strategies can achieve), and $6.63 \times 10^{6} \mathrm{RMB}$ (the median revenue that all the three strategies can achieve) for the three e-flow provision strategies. The results are listed in Table 4. Table 4 shows that the degree of flow regime alteration under the non-e-flow strategy is always greater than the degree of flow regime alteration under the other two strategies, and the degree of alteration under the second strategy is always less than the degree of alteration under the other two strategies. Thus, the incorporation of a specific e-flow strategy can result in a lower degree of flow regime alteration with the same annual revenue. It further demonstrates the importance of 


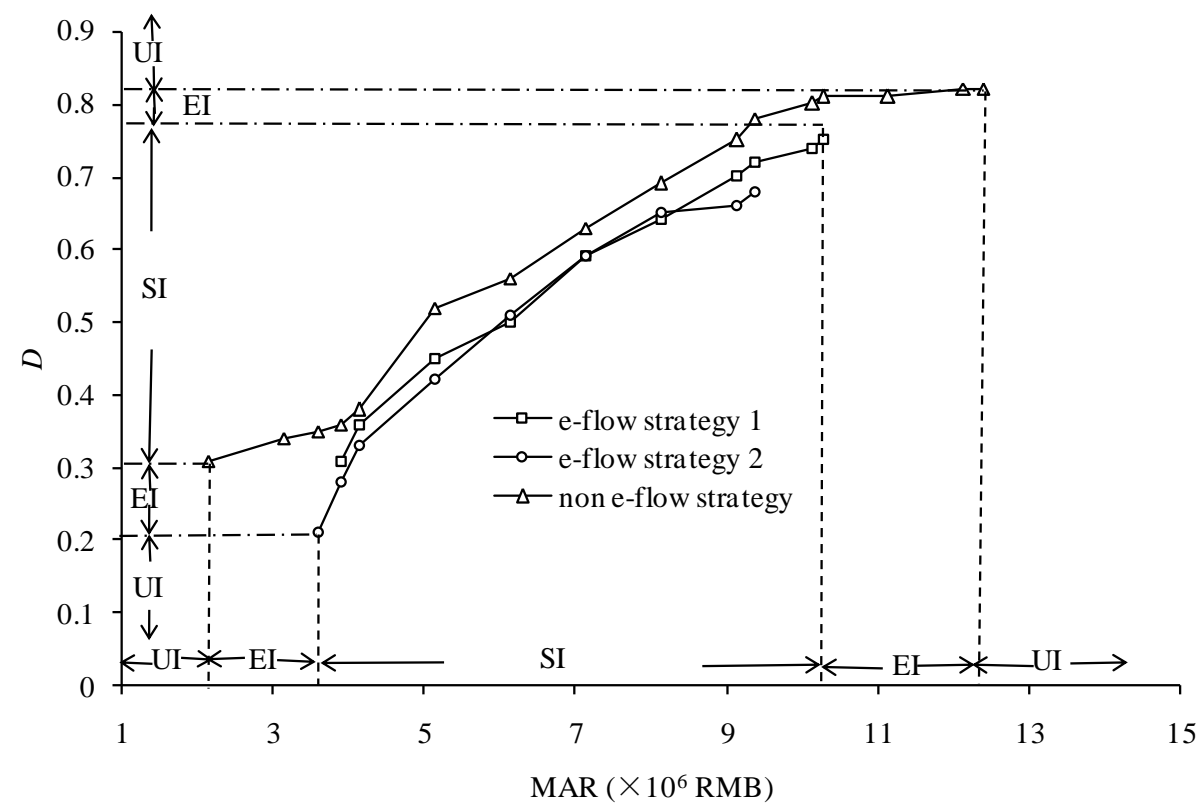

Fig. 1. Minimum degree of flow regime alteration for different planned mean revenues under three e-flow provision strategies. $D$ is the degree of flow regime alteration; MAR is the mean annual revenue; UI is the unachievable interval; EI is the exclusive interval; SI is the shared interval.

incorporatinge-flow strategy into portfolio optimisation process for a specified revenue.

\subsection{Determining the optimal e-flow provision strategy}

Different e-flow provision strategies will result in different mean annual revenues and different degrees of flow regime alteration. The basic principles for e-flow strategy determination can be stated as follows: if the planned revenue can be achieved by several e-flow strategies, the strategy that results in the lowest flow regime alteration is chosen. If the planned degree of flow regime alteration can be achieved by several eflow strategies, the strategy that results in the highest revenue should be chosen. On the basis of these principles, we have drawn the curves for mean annual revenue and minimum degree of alteration under the three e-flow provision strategies. The results are shown in Fig. 1.

On the basis of Fig. 1, the mean annual revenue can be divided into three types of intervals, i.e. exclusive intervals (the intervals that only one e-flow strategy can achieve), shared intervals (the intervals that more than one type of e-flow strategy can achieve), and unachievable intervals (the intervals that no available e-flow strategy can achieve). From the planned revenue, we can easily know which intervals the planned revenue is within. If the planned revenue is within an exclusive interval, the e-flow strategy corresponding to that interval can be applied in the portfolio optimisation process. If the planned revenue is within a shared interval, the e-flow strategy that results in the lowest degree of flow regime alteration should be applied to maintain the riverine ecosystem.
For planned revenue within an unachievable interval, if the revenue is above the highest value for all e-flow strategies, no strategy can achieve a low degree of flow regime alteration in the contract and day-ahead market. The revenue can possibly be achieved by participating in other electricity submarkets, such as the real-time balancing market (the price in this submarket can be higher, but the price is more uncertain). If the revenue is below the lowest value for all e-flow strategies, which indicates a very favourable attitude toward river protection, the hydropower producers can apply a more favourable e-flow strategy that could result in a lower degree of flow regime alteration.

On the basis of Fig. 1, the degree of flow regime alteration can also be divided into three categories, i.e. exclusive intervals (an interval that only one e-flow strategy can achieve), shared intervals (intervals that more than one type of e-flow strategy can achieve), and unachievable intervals (intervals that no e-flow strategy can achieve). Like the procedure for the mean annual revenue discussed above, the most suitable e-flow provision strategy for a planned degree of flow regime alteration can be determined. If the planned degree of flow regime alteration is within an exclusive interval, the e-flow strategy corresponding to that interval can be applied in the portfolio optimisation process. If the planned degree of alteration is within a shared interval, the e-flow strategy that results in the highest revenue should be adopted. If the planned degree of alteration is within an unachievable interval and is below the lowest value for all strategies, the hydropower producers should develop and apply more favourable e-flow strategies. 
Choosing an e-flow provision strategy is a process of compromising between hydropower producers and river protectors. The river protectors usually have the authority to ask the hydropower producers to obey some basic rules for riverine ecosystem protection, such as a minimum e-flow release. If the river protectors would like to improve the health of the riverine ecosystem by changing the hydropower generation scheme, a more ecologically favourable e-flow provision strategy should become a legal requirement, or ecological compensation should be given to the hydropower producers. On the basis of Fig. 1, we can make a preliminary assessment of the compensation criteria. For example, if the present legally required e-flow rules are to sustain the minimum e-flows and the river protectors want hydropower producers to use the second e-flow strategy, the compensation criteria should be approximately $0.9 \times 10^{6} \mathrm{RMB}$, i.e. the difference between the maximum possible mean annual revenue under the first $\left(10.27 \times 10^{6} \mathrm{RMB}\right)$ and second e-flow strategies $\left(9.37 \times 10^{6} \mathrm{RMB}\right)$.

\section{Conclusions}

Previous research on hydropower portfolio optimisation focused mainly on the maximisation of profits but neglected the requirement of riverine ecosystem protection. This research seeks mainly to remind hydropower producers of the requirement for river protection when they design portfolios and help make a shift of portfolio optimisation from economically oriented to ecologically friendly. In this study, a new framework has been developed to determine optimal hydropower portfolios considering both economic benefits and ecological needs. Within this framework, the degree of flow regime alteration is adopted as a constraint for e-flow provision and riverine ecosystem protection, and the maximisation of mean annual revenue is set as the optimisation objective. The following objectives are achieved.

- For the same planned mean annual revenue, the alteration in flow regime is lower for portfolios with e-flow provision strategies than for the portfolio without an e-flow strategy. A lower degree of alteration indicates a lower degree of river degradation. If a planned mean annual revenue can be achieved under either an e-flow strategy or a non-e-flow strategy, incorporating the eflow strategy into the portfolio optimisation process is both economically and ecologically beneficial.

- The proper e-flow provision strategy depends on the planned revenue and the planned degree of flow regime alteration. If the planned revenue can be achieved by several e-flow strategies, the strategy that results in the lowest flow regime alteration should be chosen. If the planned degree of flow regime alteration can be achieved by several e-flow strategies, the strategy that results in the highest revenue should be chosen.
In the case study of Wangkuai Reservoir, the contract and day-ahead markets participated according to the planned needs of the reservoir. In future research on portfolio optimisation in other cases that account for both riverine ecosystem and producer needs, the real-time balancing market may also participate according to the planning needs of these specific cases and the risk preferences of the hydropower producers. In these cases, the proposed framework for portfolio optimisation can also be used. The difficulties are the precise prediction of hydropower price in the real-time balancing market and the assessment of hydrological alteration at hourly time steps, which require further research.

Acknowledgements. We thank the International Science \& Technology Cooperation Program of China (no. 2011DFA72420), the National Basic Research Program of China (no. 2013CB430402), the National Science Foundation for Innovative Research Group (no. 51121003), and the National Natural Science Foundation of China (no. 51309012) for their financial support.

Edited by: Y. Cai

\section{References}

Aggarwal, S. K., Saini, L. M., and Kumarv, A.: Electricity price forecasting in deregulated markets: a review and evaluation, Int. J. Electr. Power Energ. Syst. Eng., 31, 13-22, doi:10.1016/j.ijepes.2008.09.003, 2009.

Alaywan, Z. and Wu, T.: Effects of Firm Transmission Rights on Transmission Revenue Allocation in California, available at: http://citeseerx.ist.psu.edu/viewdoc/download?doi=10. 1.1.200.1503\&rep=rep1\&type=pdf (last access: 10 December 2013), 2002.

Aly, A. A. and Peralta, R. C.: Optimal design of aquifer cleanup systems under uncertainty using a neural network and a genetic algorithm, Water Resour. Res., 35, 2523-2532, doi:10.1029/98WR02368, 1999.

Babel, M. S., Chien, N. D., Mullick, M. A., and Nanduri, U. V.: Operation of a hydropower system considering environmental flow requirements: a case study in La Nga river basin, Vietnam, J. Hydro-Environ. Res., 6, 63-73, doi:10.1016/j.jher.2011.05.006, 2011.

Bhatt, R. P. and Khanal, S. N.: A study on change in flow regime and discharge impacts on water quality of hydropower operation, Int. J. Ecol. Dev., 21, 76-88, 2012.

Bjørgan, R., Liu, C. C., and Lawarree, J.: Financial risk management in a competitive electricity market, IEEET Power Syst., 14, 1285-1291, doi:10.1109/59.801886, 1999.

Black, A. R., Rowan, J. S., Duck, R. W., Bragg, O. M., and Clelland, B. E.: DHRAM: a method for classifying river flow regime alterations for the EC Water Framework Directive, Aquat. Conserv., 15, 427-446, doi:10.1002/aqc.707, 2005.

Botterud, A., Kristiansen, T., and Ilic, M. D.: The relationship between spot and futures prices in the Nord Pool electricity market, Energ. Econ., 32, 967-978, doi:10.1016/j.eneco.2009.11.009, 2010. 
Brown, C. and King, J.: Modifying dam operating rules to deliver environmental flows: experiences from southern Africa, Int. J. River Basin Manage., 10, 13-28, doi:10.1080/15715124.2011.639304, 2012.

Bunn, S. E. and Arthington, A. H.: Basic principles and ecological consequences of altered flow regimes for aquatic biodiversity, Environ. Manage., 30, 492-507, doi:10.1007/s00267-002-27370, 2002.

Cai, Y. P., Huang, G. H., Yang, Z. F., Lin, Q. G., and Tan, Q.: Community-scale energy management systems design under uncertainty - An interval chance-constrained programming approach, Renew. Sustain. Energ. Rev., 13, 721-735, 2009.

Cai, Y. P., Huang, G. H., Tan, Q., and Yang, Z. F.: An integrated approach for climate-change impact analysis and adaptation planning under multi-level uncertainties, Part I: Methodology, Renew. Sustain. Energ. Rev., 15, 2779-2790, 2011.

Chang, F. J., Chen, L., and Chang, L. C.: Optimizing the reservoir operating rule curves by genetic algorithms, Hydrol. Process., 19, 2277-2289, 2005.

Chen, L.: Real-coded genetic algorithm optimization of long-term reservoir operation, J. Am. Water Resour. As., 39, 1157-1165, 2003.

Chen, L., McPhee, J., and Yeh, W. W.: A diversified multiobjective GA for optimizing reservoir rule curves, Adv. Water Resour., 30, 1082-1093, 2007.

Chen, Q. W., Chen, D., Li, R. N., Ma, J. F., and Blanckaert, K.: Adapting the operation of two cascaded reservoirs for ecological flow requirement of a de-watered river channel due to diversion-type hydropower stations, Ecol. Model., 252, 266-272, doi:10.1016/j.ecolmodel.2012.03.008, 2012.

Cheng, C. T., Wang, W. C., Xu, D. M., and Chau, K. W.: Optimizing hydropower reservoir operation using hybrid genetic algorithm and chaos, Water Resour. Manage., 22, 895-909, doi:10.1007/s11269-007-9200-1, 2008.

Eichhorn, A., Heitsch, H., and Römisch, W.: Scenario tree approximation and risk aversion strategies for stochastic optimization of electricity production and trading, in: Optimization in the Energy Industry, Springer, Berlin, Heidelberg, Berlin, Germany, 321346, 2009.

Fleten, S. E., Wallace, S. W., and Ziemba, W. T.: Hedging electricity portfolios via stochastic programming, IMA V. Math., 128, 7194, 2002.

Galat, D. L. and Lipkin, R.: Restoring ecological integrity of great rivers: historical hydrographs aid in defining reference conditions for the Missouri River, Hydrobiologia, 422-423, 29-48, doi:10.1023/A:1017052319056, 2000.

Gore, J. A., Layzer, J. B., and Mead, J.: Macroinvertebrate instream flow studies after 20 year: a role in stream management and restoration, Regul. River., 17, 527-542, doi:10.1002/rrr.650, 2001.

Haihe Water Conservation Commission: Comprehensive water resources planning for Hai River basin, Ministry of Water Resources of China, Tianjin, 2008.

Hebei Province Municipal Price Bureau - HPMPB: Announce for the adjustment of electricity price in Hebei Province, HPMPB, Shijiazhuang, 2009.

Holmberg, P.: Strategic forward contracting in the wholesale electricity market, Energy J., 32, 169-202, 2011.
Jager, H. I. and Smith, B. T.: Sustainable reservoir operation: can we generate hydropower and preserve ecosystem values?, River Res. Appl., 24, 340-352, doi:10.1002/rra.1069, 2008.

Karandikar, R. G., Khaparde, S. A., and Kulkarni, S. V.: Strategic evaluation of bilateral contract for electricity retailer in restructured power market, Int. J. Elec. Power, 32, 457-463, doi:10.1016/j.ijepes.2009.09.018, 2010.

Keppo, J.: Optimality with hydropower system, IEEE T. Power Syst., 17, 583-589, doi:10.1109/TPWRS.2002.800898, 2002.

Kern, J. D., Characklis, G. W., Doyle, M. W., Blumsack, S., and Whisnant, R. B.: Influence of deregulated electricity markets on hydropower generation and downstream flow regime, J. Water Res. Pl.-ASCE, 138, 342-355, doi:10.1061/(ASCE)WR.19435452.0000183, 2012.

Kranz, B., Pike, R., and Hirst, E.: Integrated electricity markets in New York, Electricity J., 16, 54-65, doi:10.1016/S10406190(03)00014-9, 2002.

Lambert, R. A.: Contracting theory and accounting, J. Account. Econ., 32, 3-87, doi:10.1016/S0165-4101(01)00037-4, 2001.

Li, Y. P., Huang, G. H., and Chen, X.: Multistage scenariobased interval-stochastic programming for planning water resources allocation, Stoch. Environ. Res. Risk. A., 23, 781-792, doi:10.1007/s00477-008-0258-y, 2009.

Ligon, F. K., Dietrich, W. E., and Trush, W. J.: Downstream ecological effects of dams, BioScience, 45, 183-192, doi:10.2307/1312557, 1995.

Lin, M. and Wu, F. L.: Trading strategy of generation companies in electricity market, Proc. CSEE, 28, 111-117, 2008.

Liu, H. L.: Research on Optimal Hydroelectric Scheduling and Risk Management in Electricity Market, Ph.D. thesis, Shanghai Jiaotong University, Shanghai, 138 pp., 2009.

Liu, H. L., Jiang, C. W., and Zhang, Y.: Portfolio management of hydropower producer via stochastic programming, Energ. Convers. Manage., 50, 2593-2599, doi:10.1016/j.enconman.2009.06.010, 2009.

Liu, X. Y., Guo, S. L., Liu, P., Chen, L., and Li, X.: Deriving optimal refill rules for multi-purpose reservoir operation, Water Resour. Manage., 25, 431-448, doi:10.1007/s11269-010-9707-8, 2011.

Miller, B. L. and Goldberg, D. E.: Optimal sampling for genetic algorithms, in: Proceedings of the Artificial Neural Networks in Engineering (ANNIE'96) Conference, 10-13 November 1996, St. Louis, USA, 291-296, 1996.

Mulder, M.: Competition and Long-Term Contracts in the Dutch Electricity Market, Competition, Contracts and Electricity Markets: a New Perspective, Edward Elgar Publishing, Northampton, 2011.

Poff, N. L., Allan, J. D., Bain, M. D., Karr, J. R., Prestegaard, K. L., Richter, B. D., Sparks, R. E., and Stromberg, J. C.: The natural flow regime: a paradigm for river conservation and restoration, BioScience, 47, 769-784, doi:10.2307/1313099, 1997.

Poff, N. L., Richter, B., Arthington, A., Bunn, S. E., Naiman, R. J., Kendy, E., Acreman, M., Apse, C., Bledsoe, B. P., Freeman, M., Henriksen, J., Jacobsen, R. B., Kennen, J., Merritt, D. M., O'Keefe, J., Olden, J., Rogers, K., Tharme, R. E., and Warner, A.: The ecological limits of hydrologic alteration (ELOHA): a new framework for developing regional environmental flow standards, Freshwater Biol., 55, 147-170, doi:10.1111/j.13652427.2009.02204.x, 2010. 
Pollitt, M.: Evaluating the evidence on electricity reform: lessons for the South East Europe (SEE) market, Util. Pol., 17, 13-23, doi:10.1016/j.jup.2008.02.006, 2009.

Ramos, L., de Sousa, J., Silva, T., Jeroìnimo, R., and Lima, J. A.: A risk management model for trading electricity in the spot market and through bilateral contracts, in: Energy Market (EEM)/2010 7th International Conference on the European, 23-25 June 2010, Madrid, Spain, 1-7, doi:10.1109/EEM.2010.5558701, 2010.

Renofalt, B., Jansson, R., and Nilsson, C.: Effects of hydropower generation and opportunities for environmental flow management in Swedish riverine ecosystems, Freshwater Biol., 55, 4967, doi:10.1111/j.1365-2427.2009.02241.x, 2009.

Richter, B. D.: Re-thinking environmental flows: from allocations and reserves to sustainability boundaries, River Res. Appl., 26, 1052-1063, doi:10.1002/rra.1320, 2010.

Richter, B. D. and Thomas, G. A.: Restoring environmental flows by modifying dam operations, Ecol. Soc., 12, 12, 2007.

Richter, B. D., Baumgartner, J. V., Powell, J., and Braun, D. P.: A method for assessing hydrologic alteration within ecosystems, Conserv. Biol., 10, 1163-1174, doi:10.1046/j.15231739.1996.10041163.x, 1996.

Richter, B. D., Baumgartner, J. V., Wigington, R., and Braun, D. P.: How much water does a river need?, Freshwater Biol., 37, 231249, doi:10.1046/j.1365-2427.1997.00153.x, 1997.

Richter, B. D., Baumgartner, J. V., Braun, D. P., and Powell, J.: A spatial assessment of hydrologic alteration within a river network, Regul. River, 14, 329-340, 1998.

Rothwell, G. S. and Gomez, T.: Electricity Economics: Regulation and Deregulation, IEEE Press, New York, 2003.

Shen, D. and Yang, Q.: Electricity market regulatory reform and competition-case study of the New Zealand electricity market, in: Energy Market Integration in East Asia: Theories, Electricity Sector and Subsidies, ERIA, Jakarta, Indonesia, 103-139, 2012.

Shiau, J. T. and Wu, F. C.: Assessment of hydrologic alterations caused by Chi-Chi diversion weir in Chou-Shui Creek, Taiwan: opportunities for restoring natural flow conditions, River Res. Appl., 20, 401-412, doi:10.1002/rra.762, 2004.

Shiau, J. T. and Wu, F. C.: Compromise programming methodology for determining instream flow under multiobjective water allocation criteria 1, J. Am. Water Resour. As., 42, 1179-1191, doi:10.1111/j.1752-1688.2006.tb05293.x, 2006.

Shiau, J. T. and Wu, F. C.: Pareto-optimal solutions for environmental flow schemes incorporating the intra-annual and interannual variability of the natural flow regime, Water Resour. Res., 43, W06433, doi:10.1029/2006WR005523, 2007.

Shiau, J. T. and Wu, F. C.: A dual active-restrictive approach to incorporating environmental flow targets into existing reservoir operation rules, Water Resour. Res., 46, W08515, doi:10.1029/2009WR008765, 2010.
Shrestha, G. B., Pokharel, B. K., Lie, T. T., and Fleten, S. E.: Medium term power planning with bilateral contracts, IEEE T. Power Syst., 20, 627-633, doi:10.1109/TPWRS.2005.846239, 2005.

State Environment Protection Administration of China: Technical guidelines for environmental impact assessment for ecological water usage, low temperature water and fish habitat facilities in hydraulics projects, report, Beijing, 2006.

Tennant, D. L.: Instream flow regimens for fish, wildlife, recreation and related environmental resources, Fisheries, 1, 6-10, doi:10.1577/1548-8446(1976)001<0006:IFRFFW>2.0.CO;2, 1976.

Tsai, C. M.: The reform paradox and regulatory dilemma in China's electricity industry, Asian Surv., 51, 520-539, 2011.

Vogel, R. M., Sieber, J., Archfield, S. A., Smith, M. P., Apse, C. D., and Huber-Lee, A.: Relations among storage, yield, and instream flow, Water Resour. Res., 43, W05403, doi:10.1029/2006WR005226, 2007.

Wang, Q. and Chen, X.: China's electricity market-oriented reform: from an absolute to a relative monopoly, Energ. Pol., 51, 143148, doi:10.1016/j.enpol.2012.08.039, 2012.

Williams, J. H. and Dubash, N. K.: Asian electricity reform in historical perspective, Pac. Aff., 77, 411-436, 2004.

Wu, J., Zheng, C., and Chien, C. C.: Cost-effective sampling network design for contaminant plume monitoring under general hydrogeological conditions, J. Contam. Hydrol., 77, 41-65, doi:10.1016/j.jconhyd.2004.11.006, 2005.

Wu, Y.: Electricity market integration: global trends and implications for the EAS region, in: Energy Market Integration in East Asia: Theories, Electricity Sector and Subsidies, ERIA, Jakarta, Indonesia, 59-81, 2012.

Yin, X. A., Yang, Z. F., and Petts, G. E.: Reservoir operating rules to sustain environmental flows in regulated rivers, Water Resour. Res., 47, W08509, doi:10.1029/2010WR009991, 2011.

Yin, X. A., Yang, Z. F., and Petts, G. E.: Optimizing environmental flows below dams, River Res. Appl., 28, 703-716, doi:10.1002/rra.1477, 2012.

Yun, R., Singh, V. P., and Dong, Z. C.: Long-term stochastic reservoir operation using a noisy genetic algorithm, Water Resour. Manage., 24, 3159-3172, doi:10.1007/s11269-010-9600-5, 2010.

Zelner, B. A., Henisz, W. J., and Holburn, G. L. F.: Contentious implementation and retrenchment in neoliberal policy reform: the global electric power industry, 1989-2001, Admin. Sci. Quart., 54, 379-412, doi:10.2189/asqu.2009.54.3.379, 2009.

Zhang, Q., Xu, C. Y., Chen, Y. D., and Yang, T.: Spatial assessment of hydrologic alteration across the Pearl River Delta, China, and possible underlying causes, Hydrol. Process., 23, 1565-1574, doi:10.1002/hyp.7268, 2009. 